Dilemmas 2015 Papers from the 18th annual International Conference Dilemmas for Human Services: Organizing, Designing and Managing

\title{
Informed Systems for Participatory Organizations Contributions from International Researchers
}

Mary M. Somerville ${ }^{1,2}$

${ }^{1}$ University Libraries, University of the Pacific, Stockton, California, USA [former Auraria Library, University of Colorado Denver, Denver,Colorado, USA],

${ }^{2}$ School of Information Systems, Science and Engineering Faculty, Queensland University of Technology, Brisbane, Australia, msomerville@pacific.edu

\begin{abstract}
Informed Systems honors stakeholder perspective and values information experience through inclusive construction of workplace systems and participatory processes. Enabling design tools and inclusive information processes support planning and building organizational communication systems for evidence based inquiry and continuous team learning. In this North American example, international researchers' contributions illustrate the efficacy of introducing theory from Australia and methods from Sweden to re-invent an academic library. To initiate transformative change at the University of Colorado Denver, Scandinavian participation design practices guided co-creation of shared vision and systems purpose.. Building upon these catalytic collective experiences, an organizational learning culture was advanced through introduction of Australian informed learning principles. This maturation model guided enactment of evidence-based decisionmaking and decision taking practices for information sharing and knowledge exchange activities. Longitudinal results suggest that such conversation-rich dialogic organization development benefits from introduction and guidance by international researchers with deep knowledge and nuanced experience.
\end{abstract}

Key words: participatory design, informed systems, informed learning

\footnotetext{
(C) 2015 Mary M. Somerville. This is an Open Access article distributed under the terms of the Creative Commons Attribution-NonCommercial 4.0 International License (http://creativecommons.org/licenses/by-nc/4.0/), permitting all non-commercial use, distribution, and reproduction in any medium, provided the orig-inal work is properly cited.

http://dx.doi.org/10.15626/dirc.2015.09
} 
Scope Note: In 2015, a 175-page research monograph titled Informed Systems: Organizational Design for Learning in Action was published by Chandos Publishing, a subsidiary of Elsevier. In that manuscript, I detail my development over more than twenty-five years of a dialogic organizational systems approach. Within this paper, I discuss the value of engaging international researchers with deep knowledge and nuanced experience to introduce and guide a multi-year Informed Systems implementation in North America.

\section{Contextual Introduction}

Participatory Design practice from Sweden (Elovaara, Igira and Mörtberg, 2006; Jansson, Mirijamdotter and Runardotter, 2010; Jansson, Mörtberg and Mirijamdotter, 2008; Jansson and Mörtberg, 2011) and informed learning theory from Australia (Bruce, 1997; 2008; Bruce, Hughes and Somerville, 2012; Somerville and Bruce, 2017) guided re-design and redirection of a North American academic library over an eight-year period, from 2008 to 2016, while I served as University Librarian at the University of Colorado Denver, USA. Workplace transformation was accelerated through multi-year engagement of international researchers serving as facilitators and coaches, who advanced theory-to-practice initiatives. Their deep disciplinary knowledge and learning centered pedagogies ensured adoption and adaption of antecedent thought to local circumstances.

Organizational transformation was advanced through a dialogic approach (Bohm, 1989) characterized by openness and transparency (Argyris, 1964). Freedom of expression was encouraged, with the aim of fostering organizational learning (Argyris and Schön, 1978) within enabling conditions for learning (Marton, 2014). This experiential learning was catalyzed and cultivated through humancentered design processes and associated professional workplace practices that initiate and enliven organizational transformation through 'working together' (Somerville, 2009).

A multidisciplinary approach, named Informed Systems (Somerville, 2015a), applied dialogic organizational development theories and principles (Bushe and Marshak, 2015) to produce transformational change through collaborative design of workplace communication systems aimed at furthering organizational learning (Somerville, 2015b). Scandinavian workplace democracy principles animated engagement strategies - i.e., organizational members were invited to participate in decision making and action taking likely to affect their work. Complementary Australian learning theories ensured that organizational capacity builds as colleagues engage in using information to learn in ever expanding professional contexts that exercise evidence-based decision-making and action-taking.

Organizational learning originated through system design and practice development activities facilitated by Swedish professor Dr. Anita Mirijamdotter (2009; 2010). Her Scandinavian design approach derived from Soft Systems Methodolo- 
gy (SSM), which originated at University of Lancaster (Checkland, 1981; 2000). Mirijamdotter studied with the founder of SSM, Professor Peter Checkland, when she was in residence in England during her doctoral studies. She was also introduced to the Australian school of relational information literacy (Bruce, 1997), when she and I co-facilitated systems design workshops in the north of Sweden in 2003.

In turn, the second international researcher, Australian professor Dr. Christine Bruce, was also conversant with the SSM approach, having served as editor for international conference proceedings (Bruce, 1992) that included a keynote address by Dr. Peter Checkland. So she was introduced early in her career to 'soft' human centered design thinking within the larger context of action learning and collaborative change initiatives prevalent at the time in Australia. Well aligned with this persistent national focus on using information to learn, Bruce published her dissertation results in her first monograph, Seven Faces of Information Literacy, in 1997, followed by a second monograph, Informed Learning, in 2008. These manuscripts have fostered appreciative inquiry around the world into local applications for using information to learn in education, workplace, and community settings. In the Colorado initiative, Bruce cultivated progressive exploration of individual and collective information experiences transferable to re-invention of service models and re-design of library facilities.

As I explain more fully in my second monograph, Informed Systems (2015a), my work as an organizational leader has been very much influenced by informed learning theory and soft systems methods. I was introduced to Soft Systems Methodology as a Fulbright Scholar in Sweden in 1991 and, following that, in 1997, I was introduced to (what has come to be known as) informed learning through reading Bruce's dissertation (1997). So Anita Mirijamdotter, Christine Bruce, and I enjoy intellectual convergence of our philosophical positions, which value variation and encourage dialogue, using information to learn with purpose. These shared values assured that, although Bruce and Mirijamdotter have only met in person once at an international conference in Lund, Sweden, their approaches were compatible. Furthermore, their ideas were compatible with my leadership approach and, in fact, shaped my leadership vision.

Our multi-year association produced a collaborative Informed Systems leadership model (Somerville, 2015a; Somerville and Chatzipanagiotou, 2015) that aims to heighten interrelationships between people and their environment through simultaneous focus on both the information and its learning context. A companion Informed Systems collaborative evidence-based information process model (Somerville, 2015a; Somerville and Chatzipanagiotou, 2015) reflects our shared commitment to participatory and inclusive 'conversation based' approaches to individual, team, and organizational learning through which workplace participants came to see the organization and its role - and their roles - in new ways. 'Learning in action' (Somerville, 2015a) within collaboratively designed conditions and 
practices served to transform the culture, here defined as 'communities where knowledge, identity, and learning are situated', in the Colorado workplace. In the sections that follow, Informed Systems initiative highlights will be described, followed by reflections about the international researchers' contributions to organizational transformation.

\section{Organizational Readiness}

An early capacity building initiative in 2009 involved library staff members in systems thinking workshops conducted by Dr. Anita Mirijamdotter, Professor of Informatics at Linnaeus University in the south of Sweden, during her Visiting Research Scholar residency at the University of Colorado Denver, USA. Within Mirijamdotter's systems thinking framework, workplace redesign purposefully fosters contextualizing information interactions that advance knowledge sharing and further community building within co-designed systems (Mirijamdotter, 2009; 2010). Toward these aims, Mirijamdotter employed a soft (human-centered) design approach, Soft Systems Methodology, developed by Professor Peter Checkland in the United Kingdom (Checkland and Holwell, 1998; Checkland and Poulter, 2006). It introduced sustainable interactive processes for initiating dialogue, creating meaning, forming intentions, and taking action related to system design and redesign (Mirijamdotter and Somerville, 2005; 2009).

These design methodologies guided participatory creation of enabling systems and information practices that further collective learning capacity (Somerville and Howard, 2010). The approach acknowledged the social context of learning - that knowledge is acquired and understood through action, interaction and sharing with others (Somerville, 2015b). Such social relationships activate and sustain organizational learning and, thereby, encourage information exchange for knowledge creation within social networks and through professional practices (Somerville, 2015a).

This Informed Systems approach recognizes that individual and team capacity is fueled by 'using information to learn' (Bruce, 1997; 2008) within ever expanding workplace contexts. Cultural practices ensure fertile conditions for learning, which guide participants' modification of the beliefs, known as worldview, that inform their actions. Intensive and explicit use of information to learn throughout the workplace (re)design process anticipated the subsequent adoption and adaption of informed learning (Somerville and Mirijamdotter, 2014; Somerville and Bruce, 2017).

\section{Workplace Activation}

In recognition of the social context of learning, including what is necessary to make sustainable learning possible (Marton, 2014), informed learning theory acknowledges that information is acquired and knowledge is generated through action, interaction, and sharing with others. Using information to learn is typically 
information focused (Somerville and Mirijamdotter, 2014) and oftentimes evidence based (Somerville and Kloda, 2016). Informed learning principles can inform collaborative creation of professional practices within workplace culture to catalyze and extend individual and group learning, with the recognition that: "Members of contemporary information and knowledge organizations must create information-rich learning environments for themselves before they can activate information-rich learning experiences for others" (Somerville, 2015b, p. 45).

Through consultation and coaching residencies in 2010, 2012, 2014, and 2015, Christine Bruce, Professor of Information Systems at Queensland University of Technology in Brisbane, Australia, advanced organization members' capacity for using information to learn. Her approach encourages appreciation of the variation in what informs self and others. Such understanding enabled collaborative creation of the conditions for learning for self and others. Philosophically well aligned with dialogic organizational development theory and practice for transformational change (Bushe and Marshak, 2015), Bruce's work enabled organization members to learn to see the organization and its role in new ways (Bruce, 2015). Her maturation model for informed workplace learning (Bruce, Hughes and Somerville, 2012) guided collective thinking processes initiated during Mirijamdotter's design thinking consultancy which were, over time and with practice, integrated into everyday work place and work space practices. In combination, these two approaches enabled co-workers to understand their organizational outcomes and professional roles in larger contexts.

\section{Informed Systems}

Informed Systems is a response to the question: "How do we activate sustainable workplace learning in a contemporary information or knowledge organization?" The name Informed Systems recognizes the combined contributions of Mirijamdotter and Bruce. Both their approaches employ a social constructionist approach that builds on peoples' experiences to intentionally activate and purposefully extend prior learning. Outcomes enrich understanding, using contextualized information to learn within a vibrant workplace ecosystem.

At the University of Colorado Denver, the international researchers together produced information-rich design experiences to advance recognition of how we learn and how others may learn. Insights prompted reconsideration of professional assumptions about how best to enable using information to learn in self and others. These reflections led to new 'habits of mind' among organizational employees, which in turn revitalized facility spaces, service models, and system interfaces (Somerville and Farner, 2012; Somerville, 2013; Somerville and Mirijamdotter, 2014; Somerville, 2015a; Somerville and Bruce, 2017). 


\section{Organizational Dilemmas}

Informed Systems recognizes the synergistic potential of enhancing information experience (Bruce, Somerville, Partridge and Stoodley, 2013; 2014) by developing new and more complex ways of working with people, information, and technology. As Bruce counseled during her coaching visits, questions such as the following are critical: "What information and learning experiences are vital to furthering our own professional work?" and "What information ... experiences do we want to facilitate or make possible for others?" (Bruce, 2013, p. 20). Exploration of these provocative thought questions was especially challenging, given the individualistic and competitive values that characterize the dominant culture of the United States (Somerville, Mirijamdotter and Collins, 2006). In contrast, cultures that exhibit collectivism and openness are most enabling for knowledge creation because members are "willing to open oneself up for new ideas, perspectives and thinking by reflecting from the experience [and] striving for continuous improvement and advancement" (Hong, 2012, p. 204).

Within the larger context of a hegemonic national culture, the first organizational dilemma therefore concerned engaging individualistic personalities in collective endeavors. In addressing this issue, the values and pedagogy used by both Bruce and Mirijamdotter served to model desired behaviors grounded in shared vision and collective action. So, for instance, in addition to presenting educational workshops on informed learning theory, which reflects the intersection of learning experience and information experience, Bruce modeled dialogic practices to encourage reflection and dialogue practice for using information to learn. Similarly, Mirijamdotter facilitated holistic and systemic co-design activities to encourage rich exchanges about variations in perspective, and, ultimately, worldview. Dialogic sessions were aimed at shaping collective vision and forging common purpose, well supported by enabling systems and professional practices.

The second dilemma emerged out of the limited time - a two-week residency in Denver, Colorado - available for Mirijamdotter's systems design facilitation. As is typical of Soft Systems Methodology interventions, a consultant enters the workplace for the life of the project and then leaves. Upon departure, systems design ceases. Then the organization has no means to improve those systems. So, in recognition of such lessons learned from Mirijamdotter's earlier academic library consultations (Somerville, 2009), a transformational leadership approach, named the Informed Systems Leadership Model (Somerville, 2015a; Somerville and Chatzipanagiotou, 2015), was developed to build conditions for perpetual workplace learning. This necessarily requires continuous evaluation and design activities to ensure the conditions needed for rethinking, repurposing, and relearning because internal and external circumstances change. In response, Informed Systems integrates informed learning capabilities, interactive evaluation and participatory systems design to ensure both workplace infrastructure and professional practices needed for persistent learning and continuous improvement. 


\section{Transformation Essentials}

Dialogic organizational development recognizes that "reality and relationships are socially constructed" (Bushe and Marshall, 2015, p. 17). Consistent with constructivist thinking, it follows that people and organizations are "meaning-making systems in which reality/truth is continuously created and re-created through social interactions and agreements, open to many possible interpretations" (Bushe and Marshall, 2015, p. 17). So it naturally follows that change in organizations very much depends on how people interact and make meaning. Language matters: it creates meaning. "Change is created and sustained by changes both in what words and symbols mean in the groups in which they are used and in the words and narratives that are used by those groups" (Bushe and Marshall, 2015, p. 17). Therefore, "creating change requires changing conversations" (Bushe and Marshall, 2015 , p. 17). This is especially challenging within contemporary organizations that are constantly in flux.

Dialogic consultants are part of the process of social (re)construction of reality, including meaning making and narrative creation (Bushe and Marshall, 2015). Therefore, it is essential that consultants' values align with those underpinning conversation-based organizational transformation. At the University of Colorado Denver, international researchers Mirijamdotter and Bruce shared common values with strong humanistic and democratic aspirations, as reflected in their highly complementary processes for exploring emerging roles for academic libraries within dynamically changing higher education landscapes. They approached organizational development with the knowledge that workplace culture evolves as "individually and collectively held assumptions about relationships and what can or cannot change" (Southern, 2015, p. 285) are changed. Together they encouraged methods of interaction, communication, and decision making within reinvented systems, structures, and policies that support change and, ultimately, transformation in understanding, through using information to learn. In addition, sustainability was furthered through model building (Somerville, Mirijamdotter, Bruce and Farner, 2014) to enable persistent refinement of human activities facilitated by systems design, activated with informed learning, and enacted through collaborative evidence-based information practices.

\section{References}

Argyris, C., 1964. Integrating the Individual and the Organization. New York: Wiley.

Argyris, C., and Schön, D. A., 1978. Organizational Learning. Reading, Massachusetts: Addison-Wesley.

Bohm, D., 1989. On Dialogue. Ojai, California. David Bohm Seminars.

Bruce, C., 1992. Transforming Tomorrow Today. In: Proceedings of the Second World Congress on Action Learning: Reflecting the philosophy of collaborative change in government, industry, education and community. Brisbane, 
Australia: Association for Action Learning, Action Research and Process Management.

Bruce, C. S., 1997. Seven Faces of Information Literacy. Adelaide, Australia: Auslib Press.

Bruce, C. S., 2008. Informed Learning. Chicago, Illinois: Association of College \& Research Libraries.

Bruce, C. S., 2013. Information literacy research and practice: An experiential perspective. Keynote address In: S. Kurbanoglu, E. Grassian, D. Mizrachi, R. Catts, and S. Spiranec (eds.), Worldwide commonalities and challenges in information literacy research and practice: European Conference on Information Literacy, ECIL 2013, Istanbul, Turkey, October 22-25, 2013. Communications in Computer and Information Science Series, vol. 397, pp. 11-30. Heidelberg, New York, Dordrecht, London: Springer. doi: 10.1007/978-3-319-03919-0

Bruce, C. S., 2015. Information literacy: Understanding people's information and learning experiences. In: Western Balkan Information Literacy: Proceedings of the 12th International Scientific Conference, pp. 11-16. Bihac, Bosnia: Cantonal and University Library Bihac.

Bruce, C. S., Hughes, H., and Somerville, M. M., 2012. Supporting learners in the 21st century. Library Trends, 60(3), pp. 522-545. doi:10.1353/lib.2012.0009

Bruce, C. S., Somerville, M. M., Stoodley, I. D., and Partridge, H. L., 2013. Diversifying information literacy research: An informed learning perspective. In: M. Hepworth and G. Walton (eds.), Developing People's Information Capabilities (pp. 223-240). Library and Information Science, Vol. 8. Bingley, England: Emerald.

Bruce, C. S., Somerville, M. M., Stoodley, I. D., and Partridge, H. L., 2014. Diversifying information literacy research: An informed learning perspective. In C. Bruce, H. Partridge, H. Hughes, K. Davis, and I. Stoodley (eds.), Information Experience: Approaches to Theory and Practice, pp. 169-186. Library and Information Science, Vol. 9. Bingley, England: Emerald. doi:10.1108/S1876-056220140000010009

Bushe, G. R., and Marshak, R. J., 2015. Introduction to the Dialogic Organization Development mindset. In: G. R. Bushe, and R. J. Marshak (eds.), Dialogic Organizational Development: The Theory and Practice of Transformational Change, pp. 11-32. Oakland, California: Berrett-Koehler Publishers, Inc.

Checkland, P. B., 1981. Systems Thinking, Systems Practice. Chichester, England: John Wiley \& Sons.

Checkland, P. B., 2000. Soft Systems Methodology: A thirty year retrospective. Systems Research and Behavioral Science, 17 (S1), pp. S11-S58.

Checkland, P. B., and Holwell, S., 1998. Information, Systems, and Information Systems: Making Sense of the Field. Chichester, England: John Wiley \& Sons. 
Checkland, P. B. and Poulter, J., (2006). Learning for Action: A Short Definitive Account of Soft Systems Methodology and its Use for Practitioners, Teachers and Students. Chichester, England: John Wiley \& Sons.

Elovaara, P., Igira, F., and Mörtberg, C., 2006. Whose participation? Whose knowledge? - Exploring PD in Tanzania-Zanzibar and Sweden. In; I. Wagner, J. Blomberg, G. Jacucci and F. Kensing (eds.), Proceedings of the Ninth Conference on Participatory Design: Expanding Boundaries in Design Volume 1, pp. 105-114. Trento, Italia: ACM Press.

Hong, J. F. L., 2012. Glocalizing Nonaka's knowledge creation model: Issues and challenges. Management Learning, 43(2), pp. 199-215.

Jansson, M., Mirijamdotter, A., and Runardotter, M., 2010. Participatory Design in Need of Angels. In: P. Elovaara, J. Sefyrin, M. B. Öhman and C. Björkman (eds.), Travelling Thoughtfulness - Feminist Technoscience Stories, RR.10.04, pp. 115-134. The Department of Informatics, Umeå University, Sweden.

Jansson, M., Mörtberg, C., and Mirijamdotter, A., 2008. Participation in e-Home Healthcare@ North Calotte. In: A. Gulz, C. Magnusson, L. Malmborg, H. Eftring, B. Jönsson and K. Tollmar, (eds.), Proceedings of the 5th Nordic Conference on Human-Computer Interaction, NordiCHI 2008: Building Bridges, Oct. 20-22, Lund, Sweden, pp. 192-200.

Jansson, M., and Mörtberg, C., 2011. A cup of coffee: Users' needs and experiences of ICT in homecare. In: M. Ziefle and C. Röcker (eds.) HumanCentered Design of E-Health Technologies: Concepts, Methods and Applications, pp. 253-271. Hershey, USA: IGI Global. doi:10.4018/9781609601775.ch011

Marton, F., 2014. Necessary Conditions of Learning. Oxford, England: Routledge. Mirijamdotter, A., and Somerville, M. M., 2005. Dynamic action inquiry: A systems approach for knowledge based organizational learning. The 11th International Conference on Human-Computer Interaction, Las Vegas, Nevada. Mahwah, New Jersey: Lawrence Erlbaum Associates, Inc.

Mirjamdotter, A., 2009. Auraria Library report on communications systems. In: M. M Somerville, 2015. Informed Systems: Organizational Design for Learning in Action. Oxford, England: Chandos Publishing, pp. 151-163.

Mirijamdotter, A., 2010. Toward collaborative evidence based information practices: Organisation and leadership essentials. Evidence Based Library and Information Practice, 5(1), pp. 17-25. Retrieved from:

http://ejournals.library.ualberta.ca/index.php/EBLIP/article/view/7221/6433

Mirijamdotter, A., and Somerville, M. M., 2009. Collaborative design: An SSMenabled organizational learning approach. International Journal of Information Technologies and Systems Approach, 2(1), pp. 48-69. 
Somerville, M. M., 2009. Working Together-Collaborative Information Practices for Organizational Learning. Chicago, Illinois: Association of College \& Research Libraries/American Library Association.

Somerville, M. M., 2013. Digital Age discoverability: A collaborative organizational approach. Serials Review, 39(4), pp. 234-239.

Somerville, M. M., 2015a. Informed Systems: Organizational Design for Learning in Action. Oxford, England: Chandos Publishing.

Somerville, M. M., 2015b. Adopting Informed Systems learning theory: How 21st century organizations can move from theory to practice. Strategic Library, issue 20 (September 15), pp. 11-15.

Somerville, M. M., and Bruce, C. S., 2017. From transaction to transformation: Organizational learning and knowledge creation experience within Informed Systems. Information Literacy in the Workplace. London, England: Facet Publishing. (in press)

Somerville, M. M., and Chatzipanagiotou, N., 2015. Informed Systems: Enabling collaborative evidence based organizational learning. Evidence Based Library and Information Practice, 10(4). doi: 10.18438/B8VP4X Available: http://ejournals.library.ualberta.ca/index.php/EBLIP/article/view/25326

Somerville, M. M., and Farner, M., 2012. Appreciative Inquiry: A transformative approach for initiating shared leadership and organizational learning. Revista de Cercetare si Interventie Sociala [Review of Research and Social Intervention] (Special issue on 'Appreciative Inquiry and social practice'), 38(September), 7-24.

Available: http://www.rcis.ro/images/documente/rcis38_01.pdf

Somerville, M. M., and Howard, Z., 2010. 'Information in context': Co-designing workplace structures and systems for organisational learning. Information Research, 15(4, December): paper 446.

Available at http://InformationR.net/ir/15-4/paper446.html

Somerville, M. M., and Kloda, L., 2016. Academic libraries. In: A. Brettle and D. Koufogiannakis (eds.), Being Evidence Based in Library and Information Practice, pp. 93-104. London, England: Facet Publishing.

Somerville, M. M., and Mirijamdotter, A., 2014. Information experiences in the workplace: Foundations for an Informed Systems Approach. In C. Bruce, H. Partridge, H. Hughes, K. Davis, and I. Stoodley (eds.), Information Experience: Approaches to Theory and Practice, pp. 203-220. Bingley, England: Emerald.

Somerville, M. M., Mirijamdotter, A., Bruce, C. S., and Farner, M., 2014. Informed Systems Approach: New directions for organizational learning. In: M. Jaabæk, M. and H. Gjengstø (eds.), International Conference on Organizational Learning, Knowledge, and Capabilities (OLKC 2014: Circuits of knowledge), Oslo, Norway: BI Norwegian Business School. Available: http://www.diva-portal.org/smash/get/diva2:714317/FULLTEXT02.pdf 
Somerville, M. M., Mirijamdotter, A., and Collins, L., 2006. Systems thinking and information literacy: Elements of a knowledge enabling workplace environment. In: Proceedings of the 39th Annual Hawaii International Conference on Systems Sciences (HICSS-39), Koloa, Kauai. Los Alamitos, California: IEEE Computer Society.

Southern, N., 2015. Framing inquiry. In: G. R. Bushe and R. J. Marshak (eds.), Dialogic Organizational Development: The Theory and Practice of Transformational Change, pp. 269-289. Oakland, California: Berrett-Koehler Publishers, Inc. 